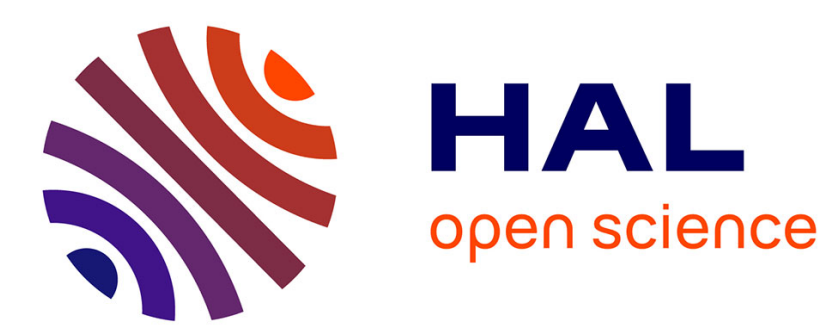

\title{
Implication of RuvABC and RecG in homologous recombination in Streptomyces ambofaciens
}

Gregory Hoff, Claire Bertrand, Emilie Piotrowski, Annabelle Thibessard, Pierre Leblond

\section{To cite this version:}

Gregory Hoff, Claire Bertrand, Emilie Piotrowski, Annabelle Thibessard, Pierre Leblond. Implication of RuvABC and RecG in homologous recombination in Streptomyces ambofaciens. Research in Microbiology, 2017, 168 (1), pp.26-35. 10.1016/j.resmic.2016.07.003 . hal-01552147

\author{
HAL Id: hal-01552147 \\ https://hal.science/hal-01552147
}

Submitted on 18 Dec 2017

HAL is a multi-disciplinary open access archive for the deposit and dissemination of scientific research documents, whether they are published or not. The documents may come from teaching and research institutions in France or abroad, or from public or private research centers.
L'archive ouverte pluridisciplinaire HAL, est destinée au dépôt et à la diffusion de documents scientifiques de niveau recherche, publiés ou non, émanant des établissements d'enseignement et de recherche français ou étrangers, des laboratoires publics ou privés.

\section{다(1)(2)}

Distributed under a Creative Commons Attribution - ShareAlikel 4.0 International 


\title{
Implication of RuvABC and RecG in Homologous Recombination in Streptomyces ambofaciens
}

\author{
Grégory Hoff $^{\text {a, b }}$, Claire Bertrand ${ }^{\text {a, b }}$, Emilie Piotrowski ${ }^{\mathrm{a}, \mathrm{b}}$, Annabelle Thibessard ${ }^{\mathrm{a}, \mathrm{b}^{*}}$, Pierre \\ Leblond ${ }^{\mathrm{a}, \mathrm{b}}$ * \\ ${ }^{\text {a } U n i v e r s i t e ́ ~ d e ~ L o r r a i n e, ~ D y n a m i q u e ~ d e s ~ G e ́ n o m e s ~ e t ~ A d a p t a t i o n ~ M i c r o b i e n n e, ~ U M R ~ 1128, ~ V a n d œ u v r e-l e ̀ s-N a n c y, ~ F-54506, ~ F r a n c e ~}$ \\ ${ }^{\mathrm{b}}$ INRA, Dynamique des Génomes et Adaptation Microbienne, UMR 1128, Vandœuvre-lès-Nancy, F-54506, France
}

E-mail addresses: gregory.hoff@univ-lorraine.fr (G. Hoff), claire.bertrand@univ-lorraine.fr (C. Bertrand), emilie.piotrowski@univ-lorraine.fr (E. Piotrowski), annabelle.thibessard@univ-lorraine.fr (A. Thibessard) *Correspondence and reprints, pierre.leblond@univ-lorraine.fr (P. Leblond) *Correspondence and reprints

Corresponding author(*): Pierre Leblond, pierre.leblond@univ-lorraine.fr, tel +33(0)383684207, Annabelle Thibessard, annabelle.thibessard@univ-lorraine.fr, tel +33(0)383684206

\begin{abstract}
Most bacterial organisms rely on homologous recombination to repair DNA double strand breaks and for the post-replicative repair of DNA single strand gaps. Homologous recombination can be divided in three steps: (i) a pre-synaptic step in which the DNA 3'-OH ends are processed, (ii) a recA dependent synaptic step allowing the invasion of an intact copy and the formation of a Holliday junctions and (iii) a post-synaptic step consisting of migration and resolution of these junctions. Currently, little is known about factors involved in homologous recombination, especially for the postsynaptic step. In Escherichia coli, branch migration and resolution are performed by the RuvABC complex, but could also rely on the RecG helicase in a redundant manner. In this study, we show that rec $G$ and ruvABC are well-conserved among Streptomyces. $\triangle$ ruvABC, $\triangle r e c G$ and $\triangle \operatorname{ruv} A B C \Delta r e c G$ mutant strains were constructed. $\triangle \operatorname{ruvABC} \triangle \operatorname{rec} G$ is only slightly affected by exposure to DNA damage (UV). We also show that conjugational recombination decreases in absence of RuvABC and RecG but that intra-chromosomal recombination is not affected. These data suggest that RuvABC and RecG are indeed involved in homologous recombination in S. ambofaciens and that alternative factors are able to take over Holliday junction in Streptomyces.
\end{abstract}

Key words : Streptomyces, homologous recombination, DNA damage, resolvase 


\section{Introduction}

Among all DNA damage that cells have to cope with, double strand breaks (DSB) are the most deleterious ones. They can be induced by various exogenous sources such as chemicals, natural products like mitomycin $\mathrm{C}$ or physical forces like desiccation or exposure to ionizing and UV radiations [1-3]. They can also be triggered by collapse of the replication fork after the replication machinery encounters a single-strand nick [4-5] or by the effect of endogenous genotoxic components such as reactive oxygen species (ROS) [6]. In absence of repair, DSBs lead to cell death, but in the course of evolution, two major ways were selected to repair DSBs: Homologous Recombination (HR) and illegitimate recombination including the errorprone Non-Homologous End Joining pathway (NHEJ). In contrast to NHEJ which can directly ligate the free DNA ends after a facultative processing step, HR needs an intact homologous template to repair the break. DNA repair through HR can be described as a sequence of three stages: the pre-synaptic, synaptic and post-synaptic steps. In bacteria, HR was previously well-documented, especially in some model organisms like Escherichia coli or Bacillus subtilis [7-15]. In the pre-synaptic step, a helicase-nuclease complex binds to the free DNA end and begins to unwind the double strand molecule while extensively degrading both strands until it reaches specific sequences named chi. The main factors involved in this step and the nature of the chi sequences can vary among organisms [11, 16-17]. The confrontation between the chi site and the helicase-nuclease complex causes important changes in the conformation of the latter complex. It leads to the alteration of the $3 '-5$ ' exonuclease activity and therefore to the formation of single strand 3' tails on which RecA protein is loaded. The newly formed RecA nucleofilament promotes homologous pairing and strand invasion during the synaptic step [9, 14]. Finally, the postsynaptic step involves the formation, migration and resolution of a four way DNA intermediate named the Holliday junction (HJ), and, at least in E. coli, PriA dependent loading of the replicative helicase on the post-synaptic DSB repair intermediate called a D-loop leads to the assembly of a replication fork and couples DSB repair with replication restart [1820].

A high number of studies concerning the postsynaptic step of HR in bacteria were undertaken in the past decades, but involvement and importance of each factor remain elusive. In E. coli, the proteins RuvA, RuvB and RuvC are known to form a tripartite complex able to displace and resolve an $\mathrm{HJ}$ [21]. In the presence of ATP, RuvA binds DNA and, together with RuvB, drives the branch migration of the HJ leading to the formation of a DNA heteroduplex [22-23]. In concert with RuvAB, RuvC resolves the newly formed structure by a dual strand incision [24]. The nicked DNA duplexes can then split up and be restored by DNA ligases [25-26]. HJ migration can also be performed by the RecG helicase [27-29]. Although the role of RuvAB in branch migration and that of RuvABC in resolution of HJs is firmly established, the role of RecG remains more elusive [30]. Recently, RecG was proposed to act on the D-loop formed by the RecA filament invasion rather than on the $\mathrm{HJ}$, and to promote the correct loading of PriA, allowing efficient replication restart and the formation of a viable recombinant molecule [31]. The additive defects conferred by $\operatorname{ruvABC}$ and $\operatorname{rec} G$ mutations would then result from the fact that $\mathrm{HJ}$ branch migration and replication restart from the D-loop are two ways of stabilizing the recombination intermediate. Even though $\operatorname{ruv} A B$ and $\operatorname{rec} G$ are highly conserved among bacterial genomes [32], the impact of their loss on cell metabolism is variable between organisms. E. coli devoid of RuvABC or RecG displays a weak sensitivity to DNA damage and a slight decrease in HR efficiency. In contrast, a double $\triangle \operatorname{ruvABC} \triangle \operatorname{rec} G$ mutant strain shows a marked aggravation of both phenotypes suggesting that the two pathways achieve redundant roles [27]. In $B$. subtilis, the single deletion of either $\operatorname{ruvAB}$, or recG or recU (a functional homologue of $r u v C$ ) is highly deleterious for cell survival to DNA damage whereas the different combinations $(\triangle r u v A B \Delta r e c U$, $\triangle r u v A B \quad \Delta r e c G$ and $\Delta$ rec $G \Delta r e c U)$ of double mutation are lethal [12-33].

Streptomyces are Gram-positive soil bacteria belonging to the Actinomycetales order. They are characterised by a complex lifestyle in which a vegetative mycelium gives rise to an aerial mycelium differentiating in spore chains. They are also known to produce a large panel of secondary metabolites. In contrast to most bacterial phyla, they possess a linear chromosomal DNA with a typical replication origin located approximately at the middle of the chromosome [34-35] and terminal proteins attached covalently to the 5' ends of the DNA [36]. The genome of the Streptomyces species presents a high plasticity characterized by frequent rearrangements resulting from both homologous recombination triggering chromosomal arm replacement [39-40] and illegitimate recombination leading for instance to chromosomal circularization (for review [39-40]). Extensive DNA amplifications are also frequently encountered on rearranged chromosomes [41] resulting from an unknown mechanism involving homologous recombination [42].

At the moment, little is known about HR factors in Streptomyces. While there is no homologue for either recBCD of $E$. coli or addAB of B. subtilis in the Streptomyces genomes so far sequenced, these bacteria possess an $a d n A B$ locus [43] as described in 
other actinomycetes [17]. This locus encodes a helicase-nuclease complex meant to play the role of recBCD and $a d d A B$ in $E$. coli and $B$. subtilis respectively, which is to process the DNA ends of a DSB and initiate the recombination repair pathway. In contrast to Mycobacterium tuberculosis, the deletion of this locus was not possible in Streptomyces ambofaciens, strongly suggesting that the encoded function was essential [43]. On the other hand, a mutant deficient for recA is viable in Streptomyces [44]. $\Delta r e c A$ strains are particularly sensitive to $\mathrm{UV}$ and mitomycin $\mathrm{C}$ exposure and are unable to perform $\mathrm{HR}$ in conjugational recombination [44]. Concerning the post-synaptic step of HR, in silico analyses revealed the presence of ruvABC and recG homologues in $S$. coelicolor and $S$. avermitilis [32], and assessing their role in $S$. ambofaciens HR is the purpose of this study.

\section{Material and methods}

\section{Bacterial strains and culture conditions.}

All strains used in this study are listed in table 1 . The DH5 $\alpha$ E.coli strain is used as conservation host for BACs and plasmids. The ET12567 non methylating strain containing the mobilising pUZ8002 plasmid was used as donor for intergeneric conjugation with $S$. ambofaciens. All E. coli strains were grown in Luria-Bertani (LB) medium at $37^{\circ} \mathrm{C}$ except for the BW25113 pKD20 thermosensitive strain used for PCR targeting, which was grown at $30^{\circ} \mathrm{C}$. S. ambofaciens ATCC23877 was our reference strain from which the mutant strains derived. All S. ambofaciens strains were grown at $30^{\circ} \mathrm{C}$ on Soya flour mannitol (SFM) plates except for UV assays which were performed on solid Hickey Tresner (HT) medium. Liquid HT medium was used for growth of mycelium before DNA extraction. When necessary, antibiotics were added to the medium at a concentration of $50 \mu \mathrm{g} / \mu \mathrm{L}$ for apramycin and kanamycin, $25 \mu \mathrm{g} / \mu \mathrm{L}$ for nalidixic acid and chloramphenicol. For intrachromosomal recombination assays, bacterial lawns were picked using a $2 \mathrm{~cm}$ diameter cookie-cutter and spores were harvested after being thoroughly vortexed (3 times $20 \mathrm{~s}$ ). For conjugational recombination assays, the number of Streptomyces spores was calibrated to $10^{8}$ UFC and added to $2.10^{8}$ UFC of the E. coli donor culture.

\section{Mutant strain construction.}

Mutant strains were constructed by PCR targeting as described by Gust et al. 2003 [51]. To summarise, a recombinant BAC containing the locus of interest was transformed in the highly recombinogenic E. coli BW25113/pKD20 strain. The target gene was replaced by an apramycin resistance disruption cassette [52] in which an oriT sequence as introduced. The modified BAC was then transferred into S. ambofaciens ATCC23877 strain using the ET12567/pUZ8002 donor host. Double-crossover (CO) events leading to the replacement of the target gene by the cassette were selected by the sensitivity to kanamycin (loss of the $\mathrm{BAC}$ vector part) along with the resistance to apramycin (insertion of the resistance cassette). The disruption cassette flanked by att $L$ and $a t t R$ sites was excised in the newly obtained mutant strains after the introduction of pOSV508 a plasmid allowing the expression of int and xis genes from pSAM2 [52]. Excision was verified by PCR after DNA extraction using a low binding sulfate salt method [53]. All the primers used in this experiment are listed in table 2.

\section{Ultraviolet (UV) light exposure and viability rates.}

Serial dilutions of the spore suspension to be tested were spread on HT plates and exposed to 0,75 and $150 \mathrm{~J} . \mathrm{m}^{-2} \mathrm{UV}$ doses using a $254 \mathrm{~nm}$ UV light. Plates were immediately protected from light to avoid photoreactivation and then incubated at $30^{\circ} \mathrm{C}$ [54]. Surviving colonies were counted after 3 days of growth, and survival rates were calculated in comparison to the same dilutions of unexposed cells of the same culture. For each condition, three biological replicates were carried out.

\section{Statistical analyses.}

For UV light exposure as well as for recombination assays, comparisons were achieved pairwise with a $t$ test under $\mathrm{R}$ and adjusted with the Bonferroni correction [55].

\section{Results}

ruvABC and recG are not essential for

Streptomyces development

In analysis aimed at identification of orthologs of DNA recombination genes, Rocha et al. [32] revealed the presence of orthologs of $\operatorname{ruvABC}$ and recG in S. coelicolor and S. avermitilis genomes. To determine whether $\operatorname{ruvABC}$ and $\operatorname{rec} G$ loci are well-conserved among Streptomyces species, we screened the 36 fully sequenced genomes of Streptomyces species (tBLASTN algorithm of the genome database of NCBI). Based on the protein sequence of the genes labelled as ruvA, ruvB, ruvC 
and recG in $S$. coelicolor, we found an ortholog for each gene in each genome with a minimal identity of $69 \%$ for $S C O 1519,82 \%$ for $S C O 1518,68 \%$ for SCO1520 and $73 \%$ for SCO5556 encoding RuvA, RuvB, RuvC and RecG respectively. The ruvABC genes are colocalised and form a potential $r u v C A B$ operon. In S. ambofaciens, RuvA, RuvB, RuvC and RecG (corresponding to SAM23877_1570, SAM23877_1569, SAM23877_1571 and SAM23877_5320) have a predicted size of respectively 201, 357, 233 and 745 amino-acids.

We employed the PCR targeting method to construct mutant strains in order to test the involvement of these genes in HR. We generated strains deleted for the $\operatorname{ruvABC}$ operon or for the rec $G$ locus as well as double mutant strains. As a HR defective control context, we targeted the recA locus. For each genotype, two independent BACs were modified by replacement of the target gene(s) by a resistance cassette and were used to generate two independent mutant strains. All the mutant strains were obtained with classical frequencies showing that none of these genes was essential for growth in laboratory conditions or requested selection for additional suppressor mutations. No specific colony morphology phenotype or sporulation deficiency was observed for the $\triangle r u v A B C$ or the $\triangle \operatorname{rec} G$ strains compared to the wild-type (WT) when grown as single colonies along a time course growth of 96 hours, corresponding to the entry in sporulation phase for the WT strain ( $\mathrm{HT}$ medium, $30^{\circ} \mathrm{C}$ ). In contrast, the double mutant $\triangle r u v A B C \Delta r e c G$ showed a growth phenotype characterised by a slight pigmentation delay (Fig. 1).

\section{The double $\triangle r u v A B C \Delta r e c G$ mutation confers sensitivity to $U V$ light exposure}

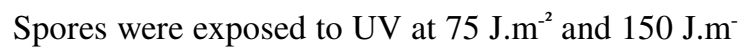
${ }^{2}$ immediately after plating on solid HT medium and survival rate was calculated relatively to unexposed cells. The WT strain showed cell survival rates of $66.45 \pm 4.29 \%$ and $25.02 \pm 2.18 \%$ at UV doses of $75{\mathrm{~J} . \mathrm{m}^{-2}}^{-2}$ and $150 \mathrm{~J} . \mathrm{m}^{-2}$ respectively (Fig. 2). The $\triangle r u v A B C$ and $\triangle$ rec $G$ strains showed a sensitivity of $61.93 \pm 3.87 \%$ and $59.12 \pm 4.51 \%$ at $75{\mathrm{~J} . \mathrm{m}^{-2}}^{-}$and $19.93 \pm 1.59 \%$ and $17.01 \pm 2.12 \%$ at $150{\mathrm{~J} . \mathrm{m}^{-2}}^{-2}$ respectively. Even if these values are slightly lower than for the WT, the difference is not statistically significant. In contrast, with sensitivity rates of

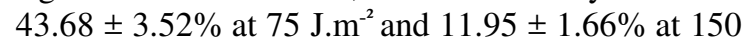

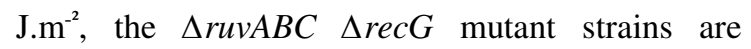
weakly but significantly more sensitive to UV exposure than the WT (at risk $\alpha=0.05$ ). This sensitivity was much less pronounced in comparison to the $\Delta r e c A$ strain which showed a drastic decrease of resistance rates with a value of $0.11 \pm 0.08 \%$ at the lowest tested dose.
The double $\triangle \mathrm{ruvABC} \Delta \mathrm{rec} G$ mutant is only affected in the formation of conjugational recombinants

To test the ability of the $\Delta \operatorname{rec} G \triangle r u v A B C$ mutant to achieve homologous recombination, we compared the mutant strains and the WT reference for their capacity to form recombinants (Fig. 3 and Fig. 4). For that purpose, we targeted a locus not implicated in DNA recombination processes (namely SAM23877_1172 encoding the Streptomyces cellobiose sensor; [56]). In a first approach (Fig. 3), we introduced by intergeneric conjugation (see material and methods section) the BAC in which SAM23877_1172 is replaced by an apramycin resistance cassette, then apramycin resistant $\left(A p r a{ }^{R}\right)$ clones were selected for and counted. By this mean, we counted all the recombination events resulting in the integration of the apramycin resistance gene into the chromosome; the most probable being a single cross-over occurring between the insert of the recombinant vector and its homologous counterpart on the chromosome (recombination within the $\mathrm{H} 1$ or $\mathrm{H} 2$ region; the event within $\mathrm{H} 1$ is represented on Fig. 3A). By doing so, we also accounted the minor proportion of recombinants that directly underwent a double cross-over leading to chromosome allele replacement (recombination within $\mathrm{H} 1$ and $\mathrm{H} 2$, Fig. 3A).

Apra $^{\mathrm{R}}$ clones resulting from single or double crossover events were counted in each genetic context and compared to the WT (Fig. 3B). The ratio of Apra $^{\mathrm{R}}$ clones obtained in $\triangle$ ruvABC and $\triangle$ recG contexts was $28.71 \pm 5.16 \%$ and $19.82 \pm 3.64 \%$ respectively relative to the WT showing that conjugational recombination efficiency was reduced on average 3.5-fold and 5-fold in $\operatorname{ruvABC}$ and in $\operatorname{rec} G$ defective mutants respectively. In the homologous recombination deficient $\operatorname{rec} A$ mutant, no Apra $^{\mathrm{R}}$ clone could be observed in the same experimental conditions. When both loci are deleted, the recombination efficiency was further reduced to $7.4 \pm 2.38 \%$ of the $\mathrm{WT}$ reference. These results demonstrated that $\operatorname{ruvABC}$ and $\operatorname{rec} G$ are involved in conjugational recombination. Since the recombination deficient phenotype is aggravated in the double $\triangle \operatorname{ruvABC} \triangle \operatorname{rec} G$ mutant strains compared to single mutants, we concluded that RuvABC and RecG may be redundant for the formation of recombinants. However, it should be noticed that in the absence of both RuvABC and RecG, HR is still effective suggesting that alternative proteins can catalyse migration and resolution of Holliday junctions in this double mutant.

Since our observations followed an intergeneric $E$. coli-Streptomyces conjugation, differences in the conjugational capacities of the WT and the $\triangle \operatorname{ruvABC} \triangle \operatorname{rec} G$ genetic backgrounds may be Res Microbiol. 2017 Jan;168(1):26-35 
responsible for the decrease in recombinants. To rule out this possibility, we set up conjugation experiments using the conjugative and integrative plasmid pDYN6902 (derived from pIJ6902); its chromosomal integration occurs by site-specific recombination and is therefore independent from HR [49]. This vector shares the same replication origin than pBeloBAC11 used to construct the BAC library [50] and is thus expected to have an equivalent copy number in the donor $E$. coli strain. Since its integration is very efficient, we monitored the conjugation frequency of the conjugative and integrative pDYN6902 plasmid in the mutant strain and compared it to the WT. There was no significant difference between both strains with conjugational rates of $1.2 .10^{-4}$ and $9.7 .10^{-5}$ for the WT and $\triangle r u v A B C \Delta \operatorname{rec} G$ strains respectively.

We further set up a second experiment to compare the frequency of homologous recombination in the different mutants (Fig. 4). In this approach, we assayed the frequency of gene replacement (SAM23877_1172 by the apramycin resistance cassette). This step corresponds to the formation of a crossing-over occurring between the long tandem repeats resulting from the integration of the recombinant BAC into the genome. The second cross-over event removes the vector DNA including the kanamycin resistance gene leading to a $A_{p r a}{ }^{R}$ $\mathrm{Kan}^{\mathrm{S}}$ phenotype from a $\mathrm{Apra}^{\mathrm{R}} \mathrm{Kan}^{\mathrm{R}}$ background. We used an experimental approach inspired from the classical Luria and Delbrück fluctuation test [57]. The idea was to test the occurrence of the second cross-over in independent samples of WT and $\triangle \operatorname{ruvABC} \triangle \operatorname{rec} G$ bacterial populations from clones that have integrated the recombinant vector by a single cross-over. Twenty samples of bacterial lawns (picked using a cookie-cutter, see material and methods section) and thus corresponding to equal subpopulations were harvested for WT and $\triangle r u v A B C \quad \triangle \operatorname{rec} G$ strains in which the first crossover happened $\left(\right.$ Apra $^{\mathrm{R}} \quad \mathrm{Kan}^{\mathrm{R}}$ transconjugants). Spore suspensions from these lawn samples were titrated and grown on HT medium supplemented with only apramycin to retain the presence of the resistance cassette but without counter-selecting the formation of the second crossing-over. Plates were further replica-plated on HT medium supplemented with both apramycin and kanamycin to determine the frequency of $\mathrm{Apra}^{\mathrm{R}} \mathrm{Kan}^{\mathrm{S}}$ clones among the $\mathrm{Apra}^{\mathrm{R}}$.

For both genetic contexts, at least one $\mathrm{Apra}^{\mathrm{R}} \mathrm{Kan}^{\mathrm{S}}$ clone was counted in each of the 20 samples of populations revealing that the second cross-over could occur at an equivalent frequency (Fig. 4B). Furthermore, Apra $^{\mathrm{R}} \mathrm{Kan}^{\mathrm{S}}$ clones were observed at frequencies which were not significantly different (risk $\alpha=0.05$ ): $13.38 \pm 4.95 \%$ and $11.67 \pm 4.98 \%$ for the WT and the $\triangle r u v A B C \triangle \operatorname{rec} G$ respectively. According to Luria and Delbrück, this reveals that intra-chromosomal homologous recombination is not significantly affected in the $\triangle \operatorname{ruvABC} \Delta \operatorname{rec} G$ double mutant strain compared to WT.

These data show that the deficiency in RuvABC and RecG does not significantly affect intrachromosomal homologous recombination in $S$. ambofaciens while it decreases the capacity to form recombinants after a conjugational transfer.

\section{Discussion}

Alternative homologous recombination postsynaptic proteins functioning in Streptomyces

RuvABC resolvasome and RecG branch migration enzyme are assumed to act as alternative proteins for the post-synaptic step of homologous recombination in E. coli $[8,58]$. While RuvAB and RecG are able to perform branch migration after $\mathrm{HJ}$ formation, the endonuclease RuvC can resolve the four way structure and restore the two double strand homologs [59]. In addition to branch migration of HJs, in vitro RecG can act on a variety of structures, and promote a variety of reactions, so that to date its role in vivo remains undetermined [30]. In this study, we found a high level of conservation of $\operatorname{ruvABC}$ and $\operatorname{rec} G$ in all Streptomyces genomes sequenced so far. We studied the involvement of both in HR in our bacterial model S. ambofaciens. For this purpose, we measured the sensitivity to UV irradiation (a DNA damaging agent), we quantified homologous recombination frequency after conjugational transfer and homologous recombination between tandemly repeated sequence on the chromosome. The $\triangle \operatorname{ruvABC} \triangle \operatorname{rec} G$ is more sensitive to UV irradiation than wild-type cells and in a $\triangle r u v A B C$ $\Delta r e c G$ mutant strain we detected a 7.4 fold decrease of HR efficiency in conjugational recombination. In contrast, no difference in intra-chromosomal recombination was observed between the mutant and the WT strain. The latter result shows that proteins may compensate for the deficiencies of RuvABC resolvasome and RecG enzyme. An open question is how to explain the significant difference in HR measured by conjugation and by intramolecular recombination assay. In conjugational HR, the substrate DNA (exogenote) is transferred from E. coli to Streptomyces as a single strand DNA. In E. coli, it is well-known that persistent single strand DNA leads to the induction of the SOS system [60]. This favours interspecies recombination through the increasing expression of $r e c A$ and $r u v A B$ [60]. Hence, we can extrapolate and hypothesise that the single-stranded transfer of the BAC DNA from E. coli to Streptomyces also stimulates the expression of these two recombination enzymes. Similarly, UV irradiation 
is known to induce the SOS response. Increased expression of RecA may stimulate the first steps of $\mathrm{HR}$, increasing the need for the enzymes that act at later steps. In contrast, intrachromosomal recombination would not be promoted by the SOSinduction of RecA and the RuvABC/RecG defect could be compensated by the basic expression of alternative resolvases.

\section{Migration and resolution of $H J$, a high redundant function?}

In the bacterial models E. coli and Bacillus subtilis RuvABC/RecU and RecG are known to be the main factors of the HR post-synaptic steps [7, 12, 33, 58]. Unexpectedly, the simultaneous inactivation of ruvABC and recG confers a mild phenotype in response to DNA damage and in HR efficiency on $S$. ambofaciens, suggesting the existence of alternative ways of processing post-synaptic molecules. In $E$. coli, when the late stages of $\mathrm{HR}$ are blocked (e.g. through ruvABC mutations), the loss of $u v r D$, known to be involved in mismatch and nucleotide excision repair, is lethal [61]. In addition, E. coli UvrD was recently shown to be able to unwind $\mathrm{HJ}$ in vitro and it could therefore have a redundant role with RuvAB and RecG [62]. In $S$. ambofaciens genome, two uvrD homologues can be detected. Another candidate for branch migration could be a recA paralog known as sms or $\operatorname{rad} A$ that is well conserved among all bacterial genomes sequenced thus far [63]. In E. coli, measurements of conjugational recombination suggest a redundant function for $\mathrm{radA} / \mathrm{sms}$ with the other branch migration factors [64]. Recently, a study showed that $\operatorname{RadA} / \mathrm{Sms}$ is able to perform branch migration but it is suspected to act differently than RuvAB and RecG since RadA/Sms displays no helicase activity [65].

For the HJ resolution activity, an alternative candidate can also be suggested. Aravind et al. [66] identified the YqgF family as sharing homologous and structural relationships with the RuvC family, suggesting that its members, predicted resolvases, could function as an alternative to RuvC. While preparing this manuscript, Nautiyal et al. [67] reported in vitro analyses carried out on RuvX (the mycobacterial member of the YqgF family). They revealed that this protein has affinity for HJs and displays HJ cleavage activity. Mycobacteria and Streptomyces both belong to the actinobacteria and an ortholog to RuvX can be identified in the Streptomyces genomes. Altogether, these data support the idea that RuvX is a serious candidate for resolving $\mathrm{HJs}_{\mathrm{s}}$ as an alternative to RuvC in S. ambofaciens. It would be interesting to investigate the involvement of the aforementioned putative alternative factors in the recombination process in Streptomyces.

\section{Conflict of interest}

The authors declare no conflict of interest.

\section{Acknowledgements}

This work was supported by the French National Research Agency program Streptoflux (ANR Blanc 0096_01), by ANR through the Laboratory of Excellence ARBRE (ANR-12- LABXARBRE-01) and by the Région Lorraine. We are grateful to Dr. Bénédicte Michel (CNRS, Gif-sur-Yvette, France) for helpful discussions and critical reading of the manuscript.

\section{References}

[1] Bonura T, Smith KC. Enzymatic production of deoxyribonucleic acid double-strand breaks after ultraviolet irradiation of Escherichia coli K-12. J Bacteriol 1975;121:511-517.

[2] Ward JF. Nature of lesions formed by ionizing radiation. DNA damage and repair, Springer; 1998; p. 65-84.

[3] Vignard J, Mirey G, Salles B. Ionizing-radiation induced DNA double-strand breaks: a direct and indirect lighting up. Radiother Oncol 2013;108:362-369.

[4] Michel B, Ehrlich SD, Uzest M. DNA double-strand breaks caused by replication arrest. EMBO J 1997;16:430-438.

[5] Mehta A, Haber JE. Sources of DNA double-strand breaks and models of recombinational DNA repair. Cold Spring Harb Perspect Biol 2014;6:a016428-a016428.

[6] Li Y, Trush MA, Yager JD. DNA damage caused by reactive oxygen species originating from a copperdependent oxidation of the 2-hydroxy catechol of estradiol. Carcinogenesis 1994;15:1421-1427.

[7] Taylor AF. Movement and resolution of Holliday junctions by enzymes from E. coli. Cell 1992;69:10631065

[8] Lloyd RG, Sharples GJ. Processing of recombination intermediates by the RecG and RuvAB proteins of Escherichia coli. Nucleic Acids Res 1993;21:17191725.

[9] Kowalczykowski SC, Eggleston AK. Homologous pairing and DNA strand exchange proteins. Annu Rev Biochem 1994;63:991-1043

[10] Myers RS, Stahl FW. Chi and the RecBCD enzyme of Escherichia coli. Annu Rev Genet 1994;28:49-70.

[11] Chedin F, Ehrlich SD, Kowalczykowski SC. The Bacillus subtilis AddAB helicase/nuclease is regulated by its cognate Chi sequence in vitro. $\mathrm{J}$ Mol Biol 2004;298:7-20.

[12] Sanchez H, Kidane D, Reed P, Curtis FA, Castillo Cozar M, Graumann PL, et al. The RuvAB branch migration translocase and RecU Holliday junction resolvase are required for double-stranded DNA break repair in Bacillus subtilis. Genetics 2005;171:873-883.

[13] Chedin F, Handa N, Dillingham MS, Kowalczykowski SC. The AddAB helicase/nuclease forms a stable

Res Microbiol. 2017 Jan;168(1):26-35 
complex with Its cognate sequence during translocation. J Biol Chem 2006;281:18610-18617.

[14] Cox MM. Motoring along with the bacterial RecA protein. Nat Rev Mol Cell Biol 2007;8:127-138.

[15] Dillingham MS, Kowalczykowski SC. RecBCD enzyme and the repair of double-stranded DNA breaks. Microbiol Mol Biol Rev 2008;72:642-671.

[16] Bianco PR, Kowalczykowski SC. The recombination hotspot Chi is recognized by the translocating RecBCD enzyme as the single strand of DNA containing the sequence 5'-GCTGGTGG-3'. Proc Natl Acad Sci U S A 1997;94:6706-6711.

[17] Sinha KM, Unciuleac M-C, Glickman MS, Shuman S. AdnAB: a new DSB-resecting motor-nuclease from mycobacteria. Genes Dev 2009;23:1423-1437.

[18] Kogoma T, Cadwell GW, Barnard KG, Asai T. The DNA replication priming protein, PriA, is required for homologous recombination and double-strand break repair. J Bacteriol 1996;178:1258-1264.

[19] Sandler SJ, Samra HS, Clark AJ. Differential suppression of priA2: Kan phenotypes in Escherichia coli $\mathrm{K}-12$ by mutations in priA, lexA, and $d n a C$. Genetics 1996;143:5-13.

[20] Sandler SJ, Marians KJ. Role of PriA in replication fork reactivation in Escherichia coli. J Bacteriol 2000;182:913

[21] Grove JI, Harris L, Buckman C, Lloyd RG. DNA double strand break repair and crossing over mediated by RuvABC resolvase and RecG translocase. DNA Repair 2008;7:1517-1530.

[22] Tsaneva IR, Müller B, West SC. ATP-dependent branch migration of Holliday junctions promoted by the RuvA and RuvB proteins of E. coli. Cell 1992 69:1171-1180.

[23] Parsons CA, Tsaneva I, Lloyd RG, West SC. Interaction of Escherichia coli RuvA and RuvB proteins with synthetic Holliday junctions. Proc Natl Acad Sci U S A 1992;89:5452-5456.

[24] Connolly B, Parsons CA, Benson FE, Dunderdale HJ, Sharples GJ, Lloyd RG, et al. Resolution of Holliday junctions in vitro requires the Escherichia coli ruvC gene product. Proc Natl Acad Sci U S A 1991;88:6063-6067.

[25] Dunderdale HJ, Benson FE, Parsons CA, Sharples GJ, Lloyd RG, West SC. Formation and resolution of recombination intermediates by $E$. coli RecA and RuvC proteins. Nature 1991;354:506-510.

[26] Iwasaki H, Takahagi M, Shiba T, Nakata A, Shinagawa H. Escherichia coli RuvC protein is an endonuclease that resolves the Holliday structure. EMBO J 1991;10:4381.

[27] Lloyd RG, Buckman C. Genetic analysis of the recG locus of Escherichia coli $\mathrm{K}-12$ and of its role in recombination and DNA repair. $\mathrm{J}$ Bacteriol 1991;173:1004-1011

[28] Lloyd RG, Sharples GJ. Dissociation of synthetic Holliday junctions by E. coli RecG protein. EMBO J 1993;12:17.

[29] Meddows TR, Savory AP, Lloyd RG. RecG helicase promotes DNA double-strand break repair. Mol Microbiol 2004;52:119-132.

[30] Lloyd RG, Rudolph CJ. 25 years on and no end in sight: a perspective on the role of RecG protein. Curr Genet. 2016; doi:10.1007/s00294-016-0589-z.

[31] Azeroglu B, Mawer JSP, Cockram CA, White MA, Hasan AMM, Filatenkova M, et al. RecG directs DNA synthesis during double-strand break repair. PLoS Genet 2016;12:e1005799.

[32] Rocha EPC, Cornet E, Michel B. Comparative and evolutionary analysis of the bacterial homologous recombination systems. PLoS Genet 2005;1:e15.

[33] Sanchez H, Carrasco B, Cozar MC, Alonso JC. Bacillus subtilis $\mathrm{RecG}$ branch migration translocase is required for DNA repair and chromosomal segregation. Mol Microbiol 2007;65:920-935.

[34] Bentley SD, Chater KF, Cerdeno-Tarraga A-M, Challis GL, Thomson NR, James KD, et al. Complete genome sequence of the model actinomycete Streptomyces coelicolor A3 (2). Nature 2002;417:141-147.

[35] Ikeda H, Ishikawa J, Hanamoto A, Shinose M, Kikuchi $\mathrm{H}$, Shiba $\mathrm{T}$, et al. Complete genome sequence and comparative analysis of the industrial microorganism Streptomyces avermitilis. Nat Biotechnol 2003;21:526531.

[36] Huang C-H, Tsai H-H, Tsay Y-G, Chien Y-N, Wang S$\mathrm{L}$, Cheng M-Y, et al. The telomere system of the Streptomyces linear plasmid SCP1 represents a novel class. Mol Microbiol 2007;63:1710-1718.

[37] Fischer G, Wenner $T$, Decaris $B$, Leblond $P$. Chromosomal arm replacement generates a high level of intraspecific polymorphism in the terminal inverted repeats of the linear chromosomal DNA of Streptomyces ambofaciens. Proc Natl Acad Sci U S A 1998;95:1429614301

[38] Uchida T, Miyawaki M, Kinashi H. Chromosomal arm replacement in Streptomyces griseus. J Bacteriol 2003; $185: 1120-1124$.

[39] Volff J-N, Altenbuchner J. Genetic instability of the Streptomyces chromosome. Mol Microbiol 1998;27:239 246.

[40] Thibessard A, Leblond P. Subtelomere plasticity in the bacterium Streptomyces, In Subtelomeres, Springer, 2014, p. 243-258.

[41] Leblond P, Demuyter P, Moutier L, Laakel M, Decaris B, Simonet J-M. Hypervariability, a new phenomenon of genetic instability, related to DNA amplification in Streptomyces ambofaciens. J Bacteriol 1989;171:419423.

[42] Volff J-N, Viell P, Altenbuchner J. Artificial circularization of the chromosome with concomitant deletion of its terminal inverted repeats enhances genetic instability and genome rearrangement in Streptomyces lividans. Mol Gen Genet 1997;253:753-760.

[43] Zhang L, Nguyen HC, Chipot L, Piotrowski E, Bertrand $\mathrm{C}$, Thibessard A, Leblond P. The $\operatorname{adn} A B$ locus, encoding a putative helicase-nuclease activity, is essential in Streptomyces. J Bacteriol 2014;196:2701-2708.

[44] Huang T-W, Chen CW. A recA null mutation may be generated in Streptomyces coelicolor. J Bacteriol 2006;188:6771-6779.

[45] Pinnert-Sindico, S. Une nouvelle espèce de Streptomyces productrice d'antibiotiques: Streptomyces ambofaciens n. sp. caractères culturaux. Ann Inst Pasteur 1954;87:702707.

[46] Hanahan D. Studies on transformation of Escherichia coli with plasmids. J Mol Biol 1983;166:557-580.

[47] MacNeil DJ, Gewain KM, Ruby CL, Dezeny G, Gibbons $\mathrm{PH}$, MacNeil T. Analysis of Streptomyces avermitilis genes required for avermectin biosynthesis utilizing a novel integration vector. Gene 1992;111:61-68.

[48] Datsenko KA, Wanner BL. One-step inactivation of

Res Microbiol. 2017 Jan;168(1):26-35 
chromosomal genes in Escherichia coli $\mathrm{K}-12$ using PCR products. Proc Natl Acad Sci U S A 2000;97:6640-6645.

[49] Thibessard A, Bertrand C, Hiblot J, Piotrowski E, Leblond P. Construction of pDYN6902, a new Streptomyces integrative expression vector designed for cloning sequences interfering with Escherichia coli viability. Plasmid 2015;82:43-49.

[50] Choulet F, Aigle B, Gallois A, Mangenot S, Gerbaud C, Truong $\mathrm{C}$, et al. Evolution of the terminal regions of the Streptomyces linear chromosome. Mol Biol Evol 2006;23:2361-2369.

[51] Gust B, Challis GL, Fowler K, Kieser T, Chater KF. PCR-targeted Streptomyces gene replacement identifies a protein domain needed for biosynthesis of the sesquiterpene soil odor geosmin. Proc Natl Acad Sci U S A 2003;100:1541-1546.

[52] Raynal A, Karray F, Tuphile K, Darbon-Rongere E, Pernodet J-L. Excisable cassettes: new tools for functional analysis of Streptomyces genomes. Appl Environ Microbiol 2006;72:4839-4844.

[53] Kieser T, Bibb MJ, Buttner MJ, Chater KF, Hopwood DA. Practical Streptomyces genetics. John Innes Foundation, Norwich, United Kingdom, 2000.

[54] Volff JN, Vandewiele D, Simonet JM, Decaris B. Ultraviolet light, mitomycin $\mathrm{C}$ and nitrous acid induce genetic instability in Streptomyces ambofaciens ATCC23877. Mutat Res 1993;287:141-156

[55] Bonferroni CE. Il calcolo delle assicurazioni su gruppi di teste, In Studii in Onore del Profesor S. O. Carboni, 1935, p. 13-60.

[56] Schlösser A, Jantos J, Hackmann K, Schrempf H. Characterization of the binding protein-dependent cellobiose and cellotriose transport system of the cellulose degrader Streptomyces reticuli. Appl Environ Microbiol 1999;65:2636-2643.

[57] Luria SE, Delbrück M. Mutations of bacteria from virus sensitivity to virus resistance. Genetics 1943;28:491-511.

[58] Whitby MC, Ryder L, Lloyd RG. Reverse branch migration of Holliday junctions by RecG Protein: a new mechanism for resolution of intermediates in recombination and DNA Repair. Cell 1993;75:341-350.

[59] Müller B, West SC. Processing of Holliday junctions by the Escherichia coli RuvA, RuvB, RuvC and RecG proteins. Experientia 1994;50:216-222.

[60] Matic I, Rayssiguier C, Radman M. Interspecies gene exchange in bacteria: the role of SOS and mismatch repair systems in evolution of species. Cell 1995;80:507515.

61] Magner DB, Blankschien MD, Lee JA, Pennington JM, Lupski JR, Rosenberg SM. RecQ promotes toxic recombination in cells lacking recombination intermediate-removal proteins. Mol Cell 2007;26:273286.

[62] Carter AS, Tahmaseb K, Compton SA, Matson SW. Resolving Holliday junctions with Escherichia coli UvrD helicase. J Biol Chem 2012;287:8126-8134.

[63] Lin Z, Kong H, Nei M, Ma H. Origins and evolution of the recA/RAD51 gene family: evidence for ancient gene duplication and endosymbiotic gene transfer. Proc Natl Acad Sci U S A 2006;103:10328-10333.

[64] Beam CE, Saveson CJ, Lovett ST. Role for radA/sms in recombination intermediate processing in Escherichia coli. J Bacteriol 2002;184:6836-6844.

[65] Cooper DL, Boyle DC, Lovett ST. Genetic analysis of
Escherichia coli RadA: functional motifs and genetic interactions. Mol Microbiol 2015;95:769-779.

[66] Aravind L, Makarova KS, Koonin EV. Holliday junction resolvases and related nucleases: identification of new families, phyletic distribution and evolutionary trajectories. Nucleic Acids Res 2000;28:3417-3432.

[67] Nautiyal A, Rani PS, Sharples GJ, Muniyappa K. Mycobacterium tuberculosis RuvX is a Holliday junction resolvase formed by dimerisation of the monomeric YqgF nuclease domain. Mol Microbiol 2016;00:00-00. 
Table 1: Strains, plasmids and BACs used in this study

\begin{tabular}{|c|c|c|}
\hline Strains, plasmids and BACs & Characteristics & Sources \\
\hline \multicolumn{3}{|l|}{ Streptomyces } \\
\hline S. ambofaciens ATCC 23877 & Used as a wild-type strain & [45] \\
\hline S. ambofaciens ATCC $23877 \triangle r u v A B C$ & Deletion of the $r u v A B C$ locus & This study \\
\hline S. ambofaciens ATCC $23877 \Delta r e c G$ & Deletion of the $\operatorname{rec} G$ locus & This study \\
\hline S. ambofaciens ATCC $23877 \Delta r e c G \Delta r u v A B C$ & Deletion of the $\operatorname{rec} G$ and the $\operatorname{ruv} A B C$ loci & This study \\
\hline S. ambofaciens ATCC $23877 \Delta r e c A$ & Deletion of the recA locus & This study \\
\hline \multicolumn{3}{|l|}{ E. coli } \\
\hline \multirow[t]{4}{*}{ DH5 $\alpha$} & $F^{-} \phi d l a c Z \Delta \mathrm{M} 15$ endA1 supE44 & {$[46]$} \\
\hline & thi-1 recAl relA1 gyrA96 deoR & \\
\hline & 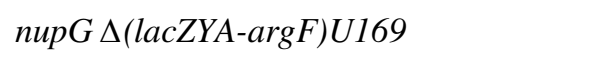 & \\
\hline & $\lambda-h s d R 17\left(r_{K}^{-} m_{k}^{+}\right) p h o A$ relAl & \\
\hline ET12567/pUZ8002 & dam-13::Tn9 dcm cat tet hsdM & [47] \\
\hline & hsdR zjj-201::Tn10 tra neo RP4 & \\
\hline \multirow[t]{2}{*}{ BW25113/pKD20 } & $\mathrm{K} 12$ derivative $\triangle a r a B A D, \triangle r h a B A D$ & [48] \\
\hline & $\begin{array}{l}\lambda \text {-RED (gam, bet, exo }), \text { bla, araC, } \\
\text { rep101 }\end{array}$ & \\
\hline \multicolumn{3}{|l|}{ Plasmids/BACs a } \\
\hline BAA8H12 $\triangle$ SAM1569-SAM1571 & $\Delta c h l:: k a n \Delta r u v A B C:: a a c 3(I V)$-oriT & This study \\
\hline BAB10F9 $\triangle$ SAM5320 & $\Delta$ chl::kan $\Delta \operatorname{recG::aac3(IV)-oriT}$ & This study \\
\hline BAB24H12 $\triangle$ SAM5320 & $\Delta c h l:: k a n \Delta \operatorname{rec} G:: a a c 3(I V)-o r i T$ & This study \\
\hline BAB20B5 $\Delta$ SAM5473 & $\Delta$ chl $:$ kan $\Delta$ recA $:$ aac3(IV)-oriT & This study \\
\hline BAB13C7 $\triangle \mathrm{SAM} 1172$ & $\Delta c h l:: k a n \Delta c e b R:: a a c 3(I V)-o r i T$ & This study \\
\hline pDYN6902 & $\begin{array}{l}\text { E. coli to Streptomyces conjugative and } \\
\text { integrative shuttle vector }\end{array}$ & [49] \\
\hline
\end{tabular}


Table 2: Primers used in this study

\begin{tabular}{|c|c|c|}
\hline Primer name & Sequence $\left(5^{\prime}-3^{\prime}\right)$ & Characteristics \\
\hline kanDchl1 & $\begin{array}{l}\text { AGGTTCCAACTTTCACCATAATGAAATAAGATCA } \\
\text { CTACCGCCCAGTTCCGCCCATTCTC }\end{array}$ & Replacement of $c h l$ by neo \\
\hline kanDchl2 & $\begin{array}{l}\text { TGTCGTGCCAGCTGCATTAATGAATCGGCCAACG } \\
\text { CGAACCATGAGATCCCCGCGCTGGA }\end{array}$ & Replacement of $c h l$ by neo \\
\hline ruv_L3 & $\begin{array}{l}\text { GTGCGCGTACTGGGGGTGGACCCGGGACTGACCC } \\
\text { GTCGCGGTGCCTCTTCGTCCCGAAGCAACTTG }\end{array}$ & $\operatorname{ruv} A B C$ deletion \\
\hline ruv_R3 & $\begin{array}{l}\text { GGACGCGGCGGGGTGAGGCCGAGGTGCGCCCAC } \\
\text { GCGGCCGGGCGCGCTTCGTTCGGGACGAAGAGG }\end{array}$ & ruvABC deletion \\
\hline ruv11 & CGAGGAATTCGGGTCGGTACTTCCTTCACA & Verification of $r u v A B C$ deletion \\
\hline ruv12 & GCGAGAATTCCATGGAGAAGGTCGACGCGT & Verification of ruvABC deletion \\
\hline D_recG_F & $\begin{array}{l}\text { TGGCGTGGTGTGCAATGGATCTCGTGCCCGCACT } \\
\text { GCGAGTGCCTCTTCGTCCCGAAGCAACTTG }\end{array}$ & $r e c G$ deletion \\
\hline D_recG_R & $\begin{array}{l}\text { TCAGCCCTTCTCCAGGTACTGCTCCCTCTCCTCGT } \\
\text { CCAGGCGCGCTTCGTTCGGGACGAAGAGG }\end{array}$ & $\operatorname{rec} G$ deletion \\
\hline V_recG_F & CGCTGCTCATCGGCGTG & Verification of $\operatorname{rec} G$ deletion \\
\hline V_recG_R & TGTGTTCCGTTCAGTCTGGC & Verification of $\operatorname{rec} G$ deletion \\
\hline DrecA_F & $\begin{array}{l}\text { GTGAAGCGATCGAATCAAGCAAACCGGGTGGAAC } \\
\text { CCATGGTGCCTCTTCGTCCCGAAGCAACTTG }\end{array}$ & recA deletion \\
\hline DrecA_R & $\begin{array}{l}\text { CCCAGTCGGTTCGTCGTGTCACGGGTCAGCTCTTG } \\
\text { GCTGCGCGCGCTTCGTTCGGGACGAAGAGG }\end{array}$ & recA deletion \\
\hline recA11 & CCGGGAATTCGGACGTACGCTCGGAGGTGC & Verification of recA deletion \\
\hline recA12 & TGGCGAATTCGTCTCCTCCGCTCACGCTCG & Verification of $r e c A$ deletion \\
\hline SaCebRmut_F & $\begin{array}{l}\text { CCGCAGAGTGCGGGGTCTCGACGGGAGGCGGAGC } \\
\text { CGATGATCGCGCGCGCTTCGTTCGGGACGAA }\end{array}$ & Deletion of SAM23877_1172 \\
\hline SaCebRmut_R & $\begin{array}{l}\text { CCGCACGGCACCCCGTGCCGCCCCGCTCCCCCAC } \\
\text { CCTCAATCTGCCTCTTCGTCCCGAAGCAACT }\end{array}$ & Deletion of SAM23877_1172 \\
\hline
\end{tabular}



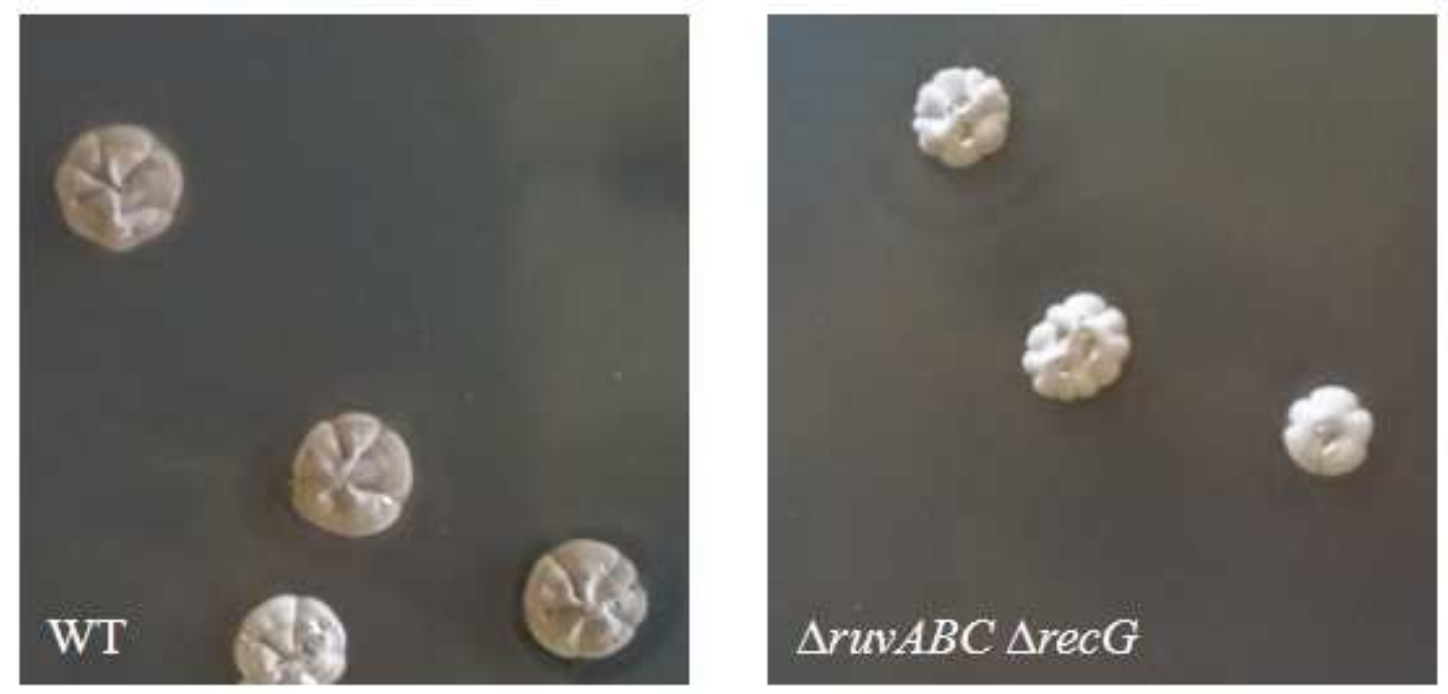

Fig.1: Phenotype of $S$. ambofaciens ATCC $23877 \mathrm{WT}$ and $\triangle r u v A B C \Delta r e c G$ strains after 96 hour growth on HT medium at $30^{\circ} \mathrm{C}$. In comparison to WT, a $\triangle r e c G \triangle r u v A B C$ strain shows a slight pigmentation delay.

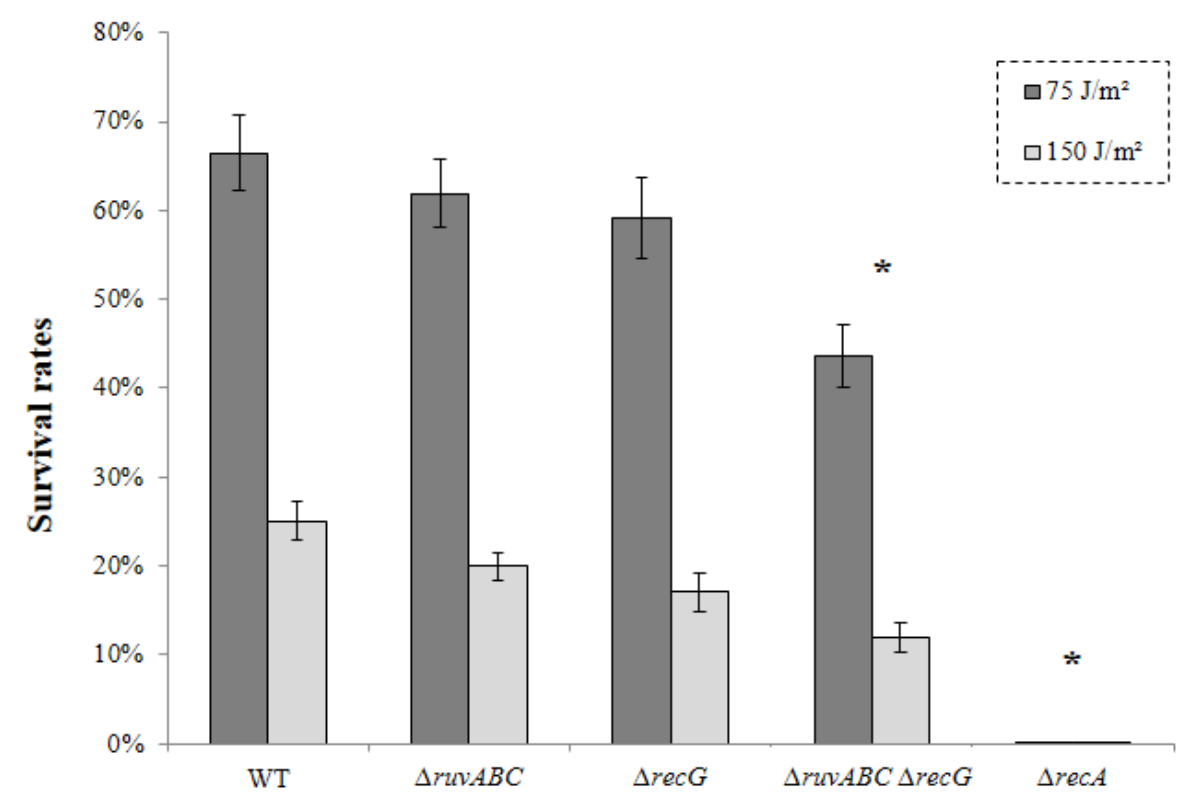

Fig.2: Survival rates of WT, $\triangle \operatorname{ruvABC,} \Delta \operatorname{rec} G, \triangle \operatorname{ruvABC} \Delta \operatorname{rec} G$ and $\triangle \operatorname{rec} A$ strains after UV exposure at $75 \mathrm{~J}^{\mathrm{m}} \mathrm{m}^{-2}$ (dark grey) and $150 \mathrm{~J} . \mathrm{m}^{-2}$ (light grey). This experiment was performed in triplicate. The asterisk $(*)$ indicates a significant difference with WT ( $t$-test $)$ at risk $\alpha=0.05$. 
A)

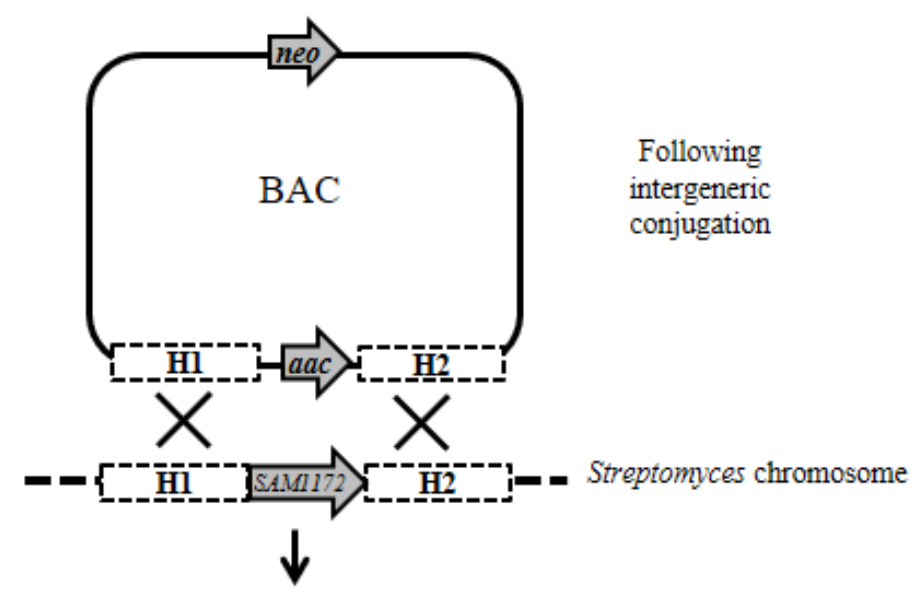

Selection for Apra ${ }^{R}$ clones

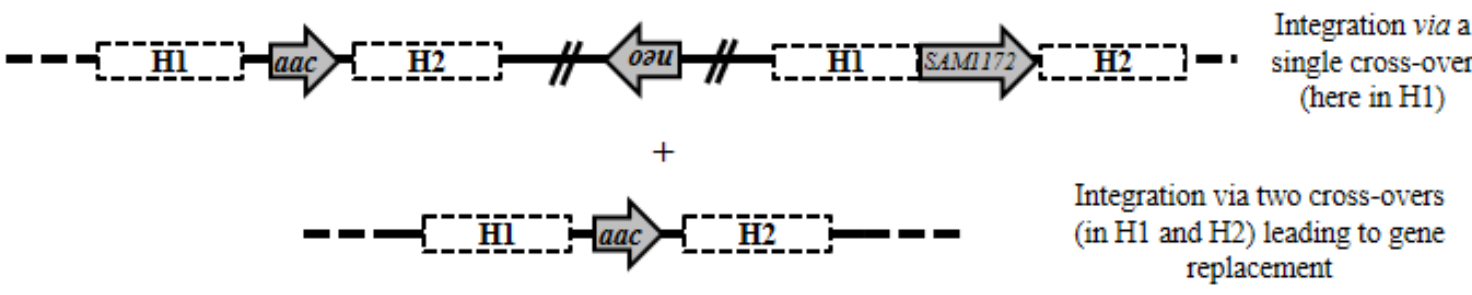

B)

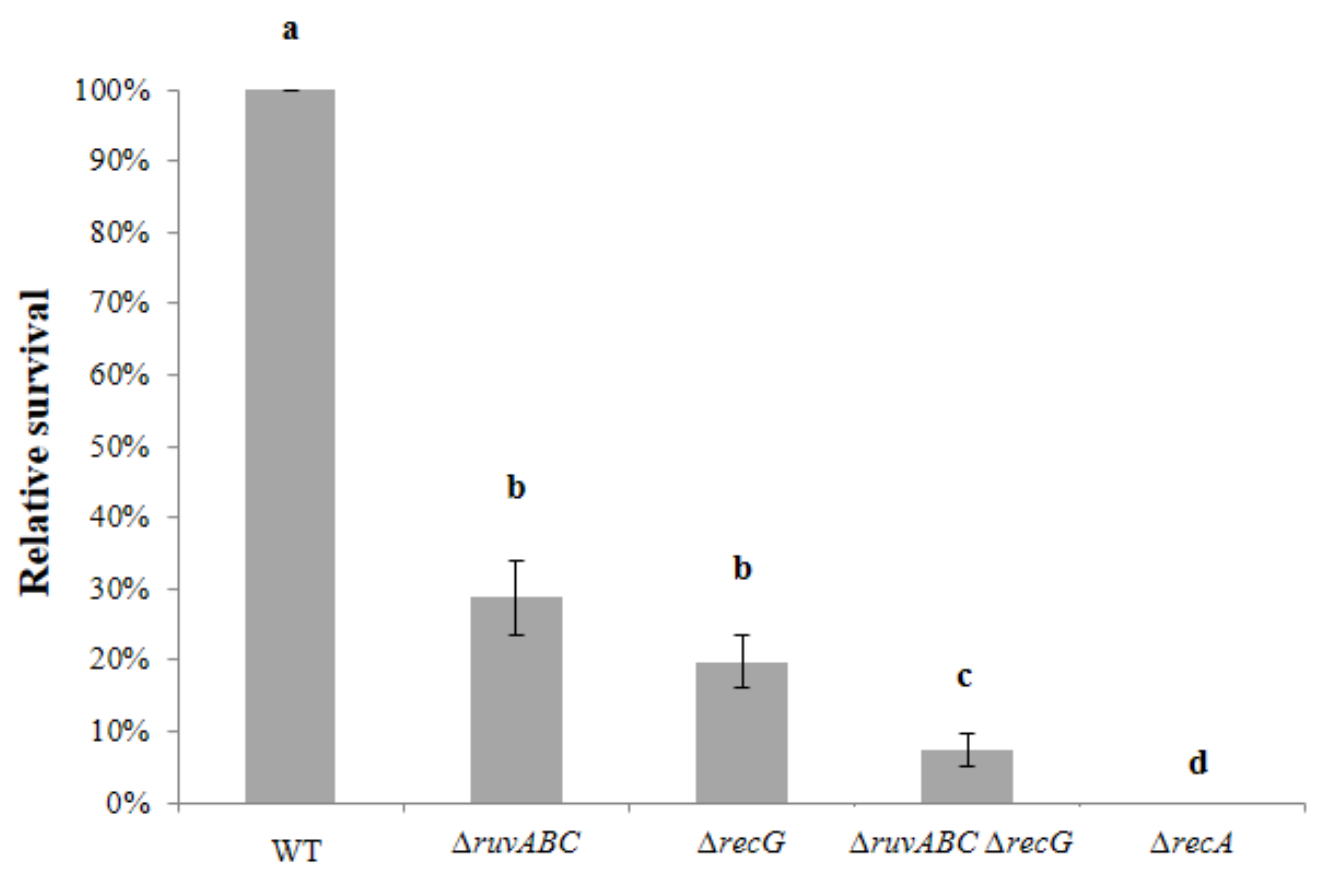

Fig.3: Conjugational recombination efficiency in S. ambofaciens. A) Representation of single or double cross-over events occurring between Streptomyces chromosome and a homologous DNA transferred by intergeneric conjugation. The neo gene confers resistance to kanamycin and $a a c$ stands for $a a c(3) I V$ which encodes the aminoglycoside 3-N-acetyltransferase and confers resistance to apramycin. B) Proportion of single and double cross-over events represented by the proportion of Apra clones obtained after conjugation in $\triangle \operatorname{ruvABC}, \triangle \operatorname{rec} G, \triangle \operatorname{ruvABC} \triangle \operatorname{rec} G, \triangle \operatorname{rec} A$ and WT strains. Values of the mutant strains were normalised to that of WT. The letters a, b, c and d indicate the different statistical groups ( $t$-test) at risk $\alpha=0.05$. 
A)

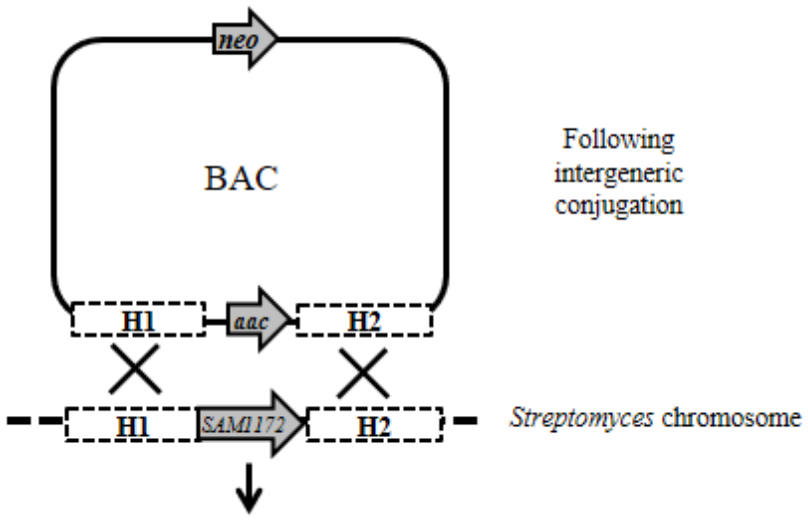

Selection for single cross-over recombinants $\mathrm{Apra}^{R} \mathrm{Kan}^{R}$ (here in $\mathrm{HI}$ )

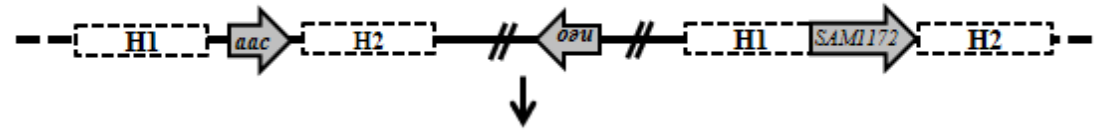

Occurrence of second cross-over Apra $^{R}$ Kan $^{S}$ (here in H2)

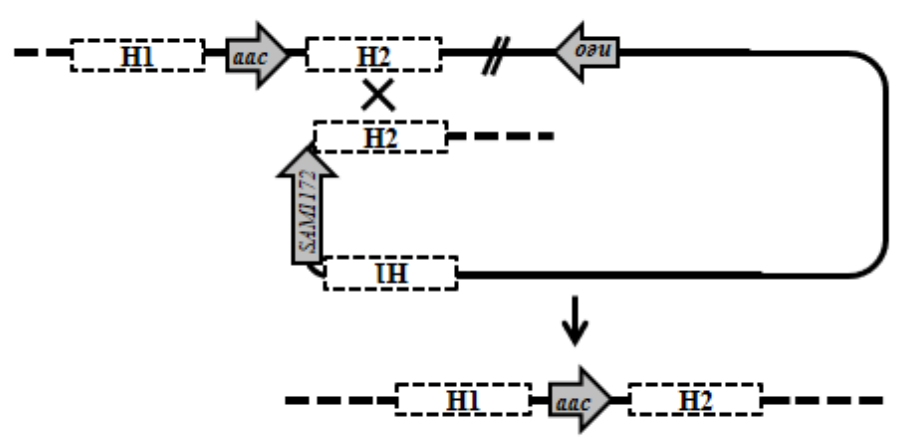

B)

WT

$\triangle r u v A B C \triangle \operatorname{rec} G$

\begin{tabular}{rrrr}
\hline Population & Total Apra $^{\mathrm{R}}$ & Apra $^{\mathrm{R}} \mathrm{Kan}^{\mathrm{S}}$ & Apra $^{\mathrm{R}} \mathrm{Kan}^{\mathrm{S}} \%$ \\
\hline 1 & 151 & 18 & $11.92 \%$ \\
2 & 80 & 17 & $21.25 \%$ \\
3 & 50 & 5 & $10.00 \%$ \\
4 & 92 & 7 & $7.61 \%$ \\
5 & 49 & 5 & $10.20 \%$ \\
6 & 43 & 6 & $13.95 \%$ \\
7 & 39 & 3 & $7.69 \%$ \\
8 & 134 & 9 & $6.72 \%$ \\
9 & 91 & 13 & $14.29 \%$ \\
10 & 34 & 6 & $17.65 \%$ \\
11 & 49 & 7 & $14.29 \%$ \\
12 & 78 & 6 & $7.69 \%$ \\
13 & 27 & 6 & $22.22 \%$ \\
14 & 110 & 17 & $15.45 \%$ \\
15 & 87 & 12 & $13.79 \%$ \\
16 & 58 & 8 & $13.79 \%$ \\
17 & 29 & 7 & $24.14 \%$ \\
18 & 32 & 3 & $9.38 \%$ \\
19 & 43 & 5 & $11.63 \%$ \\
20 & 36 & 5 & $13.89 \%$ \\
\hline & & Mean & $\mathrm{m}=13.4 \%$ \\
& & Variance & $\mathrm{V}=0.25 \%$ \\
& & & $6=4.95 \%$ \\
\hline & &
\end{tabular}

\begin{tabular}{|c|c|c|c|}
\hline Population & Total Apra ${ }^{\mathrm{R}}$ & Apra $^{\mathrm{R}} \mathrm{Kan}^{\mathrm{S}}$ & $\operatorname{Apra}^{\mathrm{R}} \mathrm{Kan}^{\mathrm{S}} \%$ \\
\hline 1 & 87 & 21 & $24.14 \%$ \\
\hline 2 & 76 & 9 & $11.84 \%$ \\
\hline 3 & 91 & 6 & $6.59 \%$ \\
\hline 4 & 131 & 10 & $7.63 \%$ \\
\hline 5 & 135 & 11 & $8.15 \%$ \\
\hline 6 & 103 & 11 & $10.68 \%$ \\
\hline 7 & 151 & 13 & $8.61 \%$ \\
\hline 8 & 143 & 20 & $13.99 \%$ \\
\hline 9 & 130 & 19 & $14.62 \%$ \\
\hline 10 & 86 & 10 & $11.63 \%$ \\
\hline 11 & 136 & 18 & $13.24 \%$ \\
\hline 12 & 107 & 19 & $17.76 \%$ \\
\hline 13 & 143 & 18 & $12.59 \%$ \\
\hline 14 & 33 & 2 & $6.06 \%$ \\
\hline 15 & 118 & 8 & $6.78 \%$ \\
\hline 16 & 160 & 7 & $4.38 \%$ \\
\hline 17 & 51 & 4 & $7.84 \%$ \\
\hline 18 & 169 & 32 & $18.93 \%$ \\
\hline 19 & 34 & 4 & $11.76 \%$ \\
\hline \multirow[t]{4}{*}{20} & 185 & 30 & $16.22 \%$ \\
\hline & & Mean & $\mathrm{m}=11.7 \%$ \\
\hline & & Variance & $\mathrm{V}=0.25 \%$ \\
\hline & Star & ard deviation & $\sigma=4.98 \%$ \\
\hline
\end{tabular}

Fig.4: Intrachromosomal recombination efficiency in S. ambofaciens. A) Representation of a second cross-over event occurring within the chromosome after a single cross-over event. B) Proportion of second cross-over events represented by the proportion of Apra $^{\mathrm{R}}{ }^{\mathrm{Kan}}{ }^{\mathrm{S}}$ clones in the 20 populations obtained after a single cross-over event in WT and $\triangle$ ruvABC $\Delta$ rec $G$ backgrounds. 